\title{
Fundamentos biológicos, ferramentas operacionais e inovação em quarentena vegetal
}

\author{
Abi Soares dos Anjos Marques(1), Marcelo Lopes-da-Silva(2), Vilmar Gonzaga(2), Fernanda Rausch Fernandes ${ }^{(1)}$, \\ Norton Polo Benito ${ }^{(2)}$ e Renato Ferraz de Arruda Veiga ${ }^{(3)}$ \\ (1)Embrapa Quarentena Vegetal, Parque Estação Biológica, Avenida W5 Norte (final), Caixa Postal 03272, CEP 70770-901 Brasília, DF, \\ Brasil. E-mail: abi.marques@embrapa.br, fernanda.rausch@embrapa.br ${ }^{(2)}$ Embrapa Recursos Genéticos e Biotecnologia, Parque Estação \\ Biológica, Avenida W5 Norte (Final), Caixa Postal 03272, CEP 70770-901 Brasília, DF, Brasil. E-mail: marcelo.lopes.silva@embrapa.br, \\ vilmar.gonzaga@embrapa.br, norton.benito@embrapa.br ${ }^{(3)}$ Instituto Agronômico, Avenida Barão de Itapura, no 1.481, Caixa Postal 28, \\ CEP 13012-970 Campinas, SP, Brasil. E-mail: renatofav53@gmail.com
}

Resumo - Ademanda por segurança alimentar e nutricional delimita modelos de intensificação da agricultura em que a prevenção de perdas na produção é essencial. O cenário de agricultura globalizada, o aumento das rotas de comércio e o deslocamento de pessoas e produtos maximiza o potencial de introduções inadvertidas de pragas em áreas indenes, colocando em risco os sistemas produtivos. A quarentena vegetal é apresentada como medida disciplinadora à movimentação de vegetais, para limitar a dispersão de pragas agrícolas. A vigilância preconiza a antecipação e reconhece a ameaça, privilegiando a acurácia e a eficiência do diagnóstico, a consolidação de metodologias de análise de risco de pragas e a evolução das ferramentas operacionais. Com apropriação de novas tecnologias, melhoria das estruturas fiscalizadoras e forte capacidade inovativa, esperam-se respostas aos desafios impostos à segurança da agricultura. Este trabalho aborda aspectos históricos relacionados às ações quarentenárias, ao arcabouço legal, à influência do comércio internacional, às ferramentas analíticas, às perspectivas de inovação e à qualificação da infraestrutura. $\mathrm{O}$ objetivo deste trabalho é contextualizar a importância do risco de introdução de novas pragas ante uma agricultura pujante e a intensificação do intercâmbio comercial. Analisa, igualmente, desafios para ações de quarentena vegetal, ao mesmo tempo em que alinha bases biológicas sobre as quais a regulação fitossanitária deve se sustentar, como subsídio para a formulação de dispositivos legais.

Termos para indexação: defesa fitossanitária, intercâmbio de germoplasma vegetal, pragas agrícolas, quarentena, segurança alimentar.

\section{Biological fundamentals, operational tools, and innovation in plant quarantine}

\begin{abstract}
The demand toward food and nutritional security delimitates models for agricultural intensification, in which yield loss prevention is essential. The globalized agriculture scenario, the increase of trade routes, and the displacement of people and products maximize the potential of nondeliberate pest introductions in undamaged areas, endangering the production systems. Plant quarantine is presented as a measure to control plant product movement, in order to limit the dispersal of agricultural pests. Surveillance advocates the anticipation and recognizes the threat, focusing on the accuracy and efficiency of the diagnosis, on the consolidation of methods of pest risk analysis, and on the evolution of operational tools. Responses to the challenges posed to agriculture security are expected, considering the appropriation of new technologies, enhancement of inspectorate structures, and a strong, innovative capacity. This work approaches the historical aspects related to quarantine actions, legal framework, influence of international trade, analytical tools, innovation perspectives, and infrastructure qualification. The objective of this work is to contextualize the risk importance of introducing new pests, faced with a thriving agriculture and the intensification of commercial interchange. It also analyses the challenges to plant quarantine actions, while it aligns the biological grounding on which the phytosanitary regulation should be sustained, in order to subside the formulation of legal security measures.
\end{abstract}

Index terms: plant protection, plant germplasm exchange, agricultural pests, plant quarantine, food security.

\section{Introdução}

A disseminação de pragas agrícolas é uma realidade com a qual os sistemas produtivos são confrontados permanentemente. Os deslocamentos globais de pessoas e produtos, cada vez mais intensos, representam um risco considerável de se introduzir pragas em áreas indenes. A associação de uma praga com seu hospedeiro é uma relação de proteção estratégica para 
a praga e que pode passar despercebida. Nesse cenário, realizar a movimentação de espécies vegetais ao redor do mundo, sem transferir pragas perigosas, é um dos maiores desafios para a humanidade (Schumann \& D’Arcy, 2012). A perspectiva dos prejuízos que podem advir da introdução de pragas, em uma área onde elas não sejam relatadas, coloca produtores e autoridades em alerta constante.

Ao longo dos últimos 60 anos, o comércio mundial se alterou, significativamente, com a formação, em 1995, da Organização Mundial do Comércio (OMC) (World Trade Organization, 1995) e com o estabelecimento de vários acordos comerciais entre países e jurisdições, visando à redução dos obstáculos ao comércio internacional. Resoluções tais como o Acordo de Medidas Sanitárias e Fitossanitárias ou "Acordo SPS" (Sanitary and Phytosanitary Agreement) têm promovido a abertura do comércio e a harmonização das medidas de biossegurança e normas agroalimentares, o que tem facilitado o movimento intracontinental $\mathrm{e}$ intercontinental de pragas que acometem os ecossistemas e cultivos (Fletcher \& Stack, 2007; Ochoa-Corona, 2011). A frequência de introduções de organismos nocivos, por meio das rotas globalizadas, aumenta exponencialmente e possibilita a emergência de pragas cujo controle e erradicação são dispendiosos (Lebas et al., 2009). O termo praga aplica-se a "qualquer espécie, estirpe ou biótipo de planta, animal ou agente patogênico prejudicial para os vegetais e produtos vegetais", assim definido no glossário de termos fitossanitários padronizado pelas Normas Internacionais de Medidas Fitossanitárias (NIMF n. ${ }^{\circ}$ 05) (International Plant Protection Convention, 2006a).

$\mathrm{O}$ estabelecimento da OMC resultou no regramento do comércio internacional das commodities agrícolas e também em um desafio aos países agroexportadores. Para o Brasil, foi necessário adequar-se às exigências das partes importadoras e, ao mesmo tempo, proteger de forma efetiva a produção agrícola para exportação e mercado interno. As limitações do sistema de defesa vegetal no Brasil derivam-se de uma legislação fitossanitária em transição, desenvolvida em uma realidade passada e que necessita adequar-se a uma demanda de regulamentação maior em curto prazo (Sugayama et al., 2015). A legislação fitossanitária tem que ser efetiva, para proteger os sistemas produtivos sem ser "protecionista" no âmbito do comércio global, ao mesmo tempo em que se depara com uma clara tendência de recrudescimento da distribuição geográfica de pragas, principalmente em direção aos países em desenvolvimento (Bebber et al., 2014).

A ampliação de mercados para produtos agrícolas, a diversificação e diminuição de custos de produção, assim como a movimentação de material genético vegetal para pesquisa científica têm uma relação direta com as atividades de quarentena vegetal. Esta revisão não pretende ser exaustiva na abrangência dos princípios de quarentena vegetal, mas abordará temas sobre problemas recorrentes, os quais limitam o desenvolvimento de processos da inovação necessária aos sistemas relacionados. Estes pontos são: uma sólida base conceitual que deveria dar suporte à legislação, considerando-se os aspectos biológicos das interações entre plantas e pragas; a adequação de avanços científicos e tecnológicos aos procedimentos quarentenários, com a finalidade de ampliar a eficiência das ações de quarentena; e as melhorias estruturais necessárias à minimização das fragilidades do sistema brasileiro de quarentena vegetal.

\section{Sanidade vegetal e quarentena: o papel estratégico de uma atividade indispensável}

Data de 1660 a primeira lei de quarentena de plantas no mundo, editada na França. Posteriormente, em 1851, o primeiro acordo internacional sobre proteção de plantas foi firmado na Europa, para disciplinar a disseminação de Viteus vitifoliae (syn Phylloxera vitifoliae), inseto introduzido dos EUA e que provocou a quase destruição dos vinhedos franceses (Berg, 1989). No Brasil, a estrutura que representou o primeiro esforço no tema defesa fitossanitária foi organizada em 1909, a qual realizava a fiscalização fitossanitária da importação de vegetais e coordenava as campanhas de erradicação de pragas em território nacional (Alves, 1980). Em 1934, o decreto n. ${ }^{\circ} 24.114$ aprovou o Regulamento de Defesa Sanitária Vegetal, que ainda está em vigor (Nóbrega, 1987). Entretanto, podese destacar o caráter avançado desse documento, em relação à época de sua redação e à contemporaneidade de muitos de seus dispositivos; esse decreto estabelece que o Ministério da Agricultura, Pecuária e Abastecimento (Mapa) pode condicionar ou mesmo proibir a importação de material vegetal, oriundo de 
países que sejam suspeitos ou assolados por pragas, com potencial de causar prejuízos ao Brasil.

Quarentena vegetal é uma das medidas para manter pragas agrícolas longe das áreas de produção, mas essa proteção somente foi reconhecida e encampada pelos governos após as catástrofes conhecidas como a requeima da batata (Phytophthora infestans), em 1845, ou a introdução de $V$. vitifoliae na Europa, em 1861. A quarentena é realizada por proibição, interceptação e eliminação de pragas, em sistemas de pré-entrada, entrada e pós-entrada relativos à movimentação de materiais, cuja regulamentação encontra-se no conjunto de leis, normas e metodologias de proteção fitossanitária e é formulada pelas autoridades governamentais (Sharma \& Thakur, 2007; Veiga et al., 2007). O sucesso das medidas de quarentena é atingido onde há equipes capacitadas que possam provocar e absorver a cooperação ativa e completa de todos os atores envolvidos. Para serem efetivas, as atividades quarentenárias necessitam ter sua base no sentido da antecipação e contar com a atenção de importadores comerciais e público em geral, conscientes das possíveis consequências da entrada, no país, de pragas exóticas (Import risk analysis handbook, 2011).

Os procedimentos ditos quarentenários não se resumem à análise de um lote recebido em um laboratório. As medidas de quarentena podem interditar importações de plantas ou produtos de certas espécies botânicas, provenientes de uma zona geográfica onde uma praga importante esteja presente, pela análise detalhada das circunstâncias que acompanham o aparecimento de sintomas, e essa decisão é tomada em razão de análise de risco. A abrangência do procedimento pode prever uma inspeção fitossanitária prévia no país de origem e análise posterior à introdução no país importador. A análise oficial deve ser validada em laboratório, com a utilização das mais eficientes técnicas de diagnose disponíveis, sejam biológicas, bioquímicas, sorológicas ou moleculares. Completando o quadro de medidas, estabelecem-se tratamentos prévios de desinfestação e desinfecção, tanto no país importador quanto no exportador, assim como tratamentos que visem à erradicação dos contaminantes posteriores à interceptação (Lepoivre, 2003).

Culturas hoje utilizadas para alimentação e fibras evoluíram de áreas geográficas restritas. O movimento de plantas e suas partes para uso em melhoramento genético é largamente praticado com o objetivo de desenvolver a produção agrícola (Marques \& Fernandes, 2015). No entanto, a produção agrícola mundial encontra-se constantemente ameaçada pela dispersão de organismos nocivos aos cultivos, por meio do intenso fluxo comercial entre os países (Ebbels, 2003) e cada nova praga introduzida representa aumento do custo de produção (Import risk analysis handbook, 2011).

Muitos países regulam a importação de materiais vegetais, mas, na maioria dos casos, a importação para fins científicos é permitida com ressalvas apropriadas (Waterworth \& White, 1982; Brasil, 1998; Legrand, 2012), quer seja solicitada por empresas particulares quer por instituições oficiais. Nesse intenso trânsito de materiais, o bioterrorismo relacionado a pragas agrícolas é um tema pouco difundido, porém, há estudos que propõem o desenvolvimento de análises sobre o princípio da liberação hostil de pragas dessa natureza, tendo como modelo a extensa documentação existente sobre liberação intencional de patógenos humanos (Ancona et al., 2010).

Diante disto, os princípios que norteiam as quarentenas são sustentados por leis e seguem pré-requisitos fundamentais. Entre eles, podem-se mencionar: as medidas são baseadas em princípios biológicos; o propósito de prevenção não pode ser confundido com barreira não tarifária ao livre comércio; leis e processos devem ser dinâmicos e devem ser revistos continuamente, em face de mudanças de condicionantes; quarentenas efetivas são suportadas por legislação compreensível e cooperação entre autoridades e público em geral (Kahn \& Mathur, 1999; Import risk analysis handbook, 2011).

\section{Comércio e questões fitossanitárias}

Em 1947, ocorreu a primeira rodada de negociações comerciais multilaterais, a Rodada de Genebra, que contou com 23 países, inclusive o Brasil, que assinaram o Acordo Geral sobre Tarifas e Comércio (Gatt). Este acordo resultou de um conjunto de normas e de um grande número de concessões tarifárias, que objetivaram combater práticas protecionistas de países e impulsionar a liberalização comercial internacional. Na Rodada de Tóquio do Gatt (1973-1979), foi estabelecido o Standards Code (Código de Normas), de adesão voluntária, cujo escopo consistia em disciplinar o tema de regulamentos técnicos, inclusive as medidas 
de natureza sanitária. A disciplina sobre esse assunto avançou durante a Rodada do Uruguai (1986-1993), quando o Código de Normas foi sucedido por dois novos acordos, o Acordo SPS e o Acordo Sobre Barreiras Técnicas ao Comércio (Agreement on Technical Barriers to Trade - TBT). A diferença básica entre os dois está em seus objetivos e, portanto, em sua abrangência (Miranda et al., 2004).

A partir da criação da OMC, em 1995, os problemas fitossanitários e sanitários passaram a ser regulados pelo Acordo SPS. Entre as diretivas desse acordo, estabeleceu-se que a imposição de obstáculos à livre importação de produtos agrícolas deve acontecer somente com provas científicas de riscos da prática da importação. As questões relativas ao Acordo SPS devem ser encaminhadas aos respectivos pontos focais, de forma a se obter uma resposta satisfatória e resultados em um desdobramento adequado. O Brasil tem dois pontos focais para o Acordo SPS. Um deles é a Secretaria de Defesa Agropecuária (SDA), do Mapa, por meio da sua Organização Nacional de Proteção Fitossanitária (ONPF), papel que é desempenhado pelo Departamento de Sanidade Vegetal (DSV). O outro ponto focal é a Agência Nacional de Vigilância Sanitária (Anvisa), do Ministério da Saúde, aos quais são remetidas as dúvidas que envolvem produtos agropecuários e aquelas relacionadas a questões sanitárias, respectivamente. Os decretos que aprovaram o GATT, o Acordo SPS e a OMC levam ao compromisso entre países signatários de somente imporem restrições ao comércio internacional de materiais vegetais, se houver respaldo científico para a medida. Assim, à proporção que as restrições tarifárias vão sendo resolvidas por meio de negociações, as restrições fitossanitárias ganham destaque (Silva, 2000).

As questões fitossanitárias e sanitárias relacionadas ao comércio internacional de commodities agrícolas estão regulamentadas no Acordo SPS (World Trade Organization, 1995). No âmbito desse acordo, emergiu o conceito de "nível apropriado de proteção" que, em parte, está materializado na regulamentação de medidas fitossanitárias acordadas entre países. Assim, a medida regulamentada resulta em diminuição do risco de introdução de praga, é economicamente viável e não deve ser mais restritiva do que outras disponíveis para se alcançar o mesmo nível de proteção. O nível apropriado de proteção passou a ser referido como "nível aceitável de risco" (World Trade
Organization, 1995). O Acordo SPS definiu que as medidas fitossanitárias que são adotadas no comércio internacional de commodities agrícolas devem ser baseadas na avaliação de risco. O risco da praga é tido como produto da probabilidade de um evento adverso (introdução e disseminação) e a magnitude de suas consequências. As medidas fitossanitárias devem ser direcionadas para esse risco e para suas consequências econômicas potenciais (International Plant Protection Convention, 2006b; Griffin, 2012). Este processo é conhecido como avaliação de risco da praga e ocorre de forma ex ante. Como a avaliação de risco procede de uma identificação da fonte de risco e é sucedida pelo manejo de risco, a denominação de todo o processo é chamado de análise de risco de pragas (ARP) (Devorshak, 2012) e está padronizado na NIMF 11 (International Plant Protection Convention, 2013). Cada país tem a soberania de estabelecer o nível de risco que julgar aceitável.

No Brasil, a importação de material vegetal com fins comerciais está condicionada à realização de ARP, salvo algumas exceções, e está regulamentada pela Instrução Normativa n. ${ }^{\circ} 6$ de 2005 (Brasil, 2005). Da mesma forma, a definição das listas de pragas quarentenárias necessita do aporte de informações das ARPs. O processo de ARP gera uma documentação extensa e é extremamente dependente de informações disponíveis sobre as pragas. Apesar disso, nas duas vertentes de uso, o processo é uma ferramenta poderosa e determinativa.

\section{Ferramentas operacionais}

\section{Ferramentas legais: legislação local e dispositivos internacionais}

O decreto brasileiro de 1934 é constantemente atualizado pelas portarias e instruções normativas do Mapa e pelas interministeriais, que têm por objetivo incorporar a demanda dos novos cenários internos e internacionais (Silva, 2000). Por outro lado, a legislação fitossanitária mundial é regida pela Organização das Nações Unidas para a Agricultura e a Alimentação (FAO), a qual é, igualmente, revisada e atualizada. Como organização supranacional, a FAO realizou, em 1951, a Convenção Internacional de Proteção de Vegetais (CIPV), tratado firmado entre 177 países, inclusive o Brasil, para estabelecer os regulamentos fitossanitários. 
A CIPV e a Organização Mundial de Saúde Animal são reconhecidas dentro do Acordo SPS como os órgãos que harmonizam os padrões internacionais das medidas sanitárias e fitossanitárias. A Comissão de Medidas Fitossanitárias (CMF) governa a CIPV e aprova as NIMFs, que são preparadas como parte do programa global de política e assistência técnica em quarentena vegetal da FAO. Esse programa disponibiliza os padrões, diretrizes e recomendações para a harmonização internacional das medidas fitossanitárias, a fim de facilitar o comércio e evitar barreiras injustificadas. Como estímulo à cooperação entre governos, a CIPV coordenou a formação das Organizações Regionais de Proteção Fitossanitária (ORPFs), formadas por grupos de países geograficamente próximos, as quais estabeleceram diretrizes em requisitos fitossanitários no que concerne ao comércio e à pesquisa. A primeira organização criada foi a European and Mediterranean Plant Protection Organization (EPPO), em 1951. A mais recente é a Pacific Plant Protection Organization (PPPO), fundada em 1995, e atualmente há nove organizações desse tipo (Lepoivre, 2003) (Tabela 1). Em se tratando de pragas cuja dispersão pode se dar livremente através das fronteiras, o desenvolvimento e aplicação de soluções requerem cooperação internacional (Sharma \& Thakur, 2007). Em 1980, Argentina, Brasil, Chile, Paraguai e Uruguai constituíram o Comitê de Sanidade Vegetal do Cone Sul (Cosave), reorganizado em 1989, com o objetivo de estabelecer regulamentos fitossanitários para o intercâmbio seguro de produtos vegetais entre os países do Mercado Comum do Sul (Mercosul) (Marinho, 2001). Os acordos comerciais entre esses países e a OMC garantem a livre circulação de bens,

Tabela 1. Organizações regionais de proteção fitossanitária (ORPFs), (Regional Plant Protection Organizations - RPPO) organizadas sob os auspícios da CIPV/FAO no domínio da proteção de plantas (Lepoivre, 2003).

\begin{tabular}{|c|c|c|}
\hline Organização & Ano de fundação & Países participantes \\
\hline $\begin{array}{l}\text { European and Mediterranean Plant } \\
\text { Protection Organization (EPPO) }\end{array}$ & 1951 & $\begin{array}{l}\text { Albânia, Argélia, Áustria, Bélgica, Bulgária, Croácia, Chipre, Dinamarca, Espanha, } \\
\text { Finlândia, França, Alemanha, Grécia, Guernsey, Hungria, Irlanda, Irlanda do Norte, Israel } \\
\text { Itália, Jersey, Jordânia, Quirguistão, Letônia, Lituânia, Luxemburgo, Macedônia, Malta } \\
\text { Marrocos, Países Baixos, Noruega, Polônia, Portugal, Romênia, Reino Unido, Rússia, } \\
\text { Eslováquia, Eslovênia, Suécia, Suíça, Tunísia, República Tcheca, Ucrânia. }\end{array}$ \\
\hline $\begin{array}{l}\text { Organismo Internacional Regional de } \\
\text { Sanidad Agropecuaria (OIRSA) }\end{array}$ & 1953 & Belize, Costa Rica, El Salvador, Guatemala, Honduras, México, Nicarágua e Panamá. \\
\hline $\begin{array}{l}\text { Interafrican Phytossanitary Council } \\
\text { (IAPSC) }\end{array}$ & 1954 & $\begin{array}{l}\text { Argélia, Angola, Benim, Botsuana, Burkina Faso, Burundi, Camarões, Cabo-Verde, } \\
\text { República Centro-Africana, Chade, República Democrática do Congo, República } \\
\text { do Congo, Costa do Marfim, Djibuti, Egito, Etiópia, Gabão, Gâmbia, Gana, Guiné } \\
\text { Equatorial, Guiné-Bissau, Quênia, Lesoto, Libéria, Líbia, Madagascar, Malauí, } \\
\text { Mauritânia, Moçambique, Namíbia, Níger, Nigéria, Ruanda, São Tomé, Senegal, Ilhas } \\
\text { Seychelles, Serra Leoa, Somália, África do Sul, Sudão, Suazilândia, Togo, Tunísia, } \\
\text { Uganda, Tanzânia, Zâmbia, Zimbábue. }\end{array}$ \\
\hline $\begin{array}{l}\text { Asia and Pacific Plant Protection } \\
\text { Commission (APPPC) }\end{array}$ & 1956 & $\begin{array}{l}\text { Austrália, Bangladesh, Camboja, China, Fiji, Polinésia Francesa, Índia, Indonésia, Laos, } \\
\text { Malásia, Birmânia, Nepal, Nova Zelândia, Paquistão, Papua-Nova Guiné, Filipinas, } \\
\text { República da Coréia, Salomão (Ilhas), Samoa Ocidental, Sri Lanka, Tailândia, Tonga, } \\
\text { Vietnã. }\end{array}$ \\
\hline $\begin{array}{l}\text { Caribbean Plant Protection } \\
\text { Commission }(\mathrm{CPPC})^{(1)}\end{array}$ & 1967 & $\begin{array}{l}\text { Barbados, Colômbia, Costa Rica, Cuba, Dominica, Estados Unidos (Ilhas Virgens } \\
\text { Americanas e Porto Rico), França (Guadalupe, Guiana Francesa e Martinica), Granada } \\
\text { Guiana, Haiti, Jamaica, México, Países Baixos (Aruba, Antilhas Holandesas), Nicarágua } \\
\text { Panamá, Reino Unido (Ilhas Virgens Britânicas), São Cristóvão e Névis, Santa Lúcia } \\
\text { Suriname, Trinidad e Tobago, Venezuela. }\end{array}$ \\
\hline Comunidad Andina (CA) & 1969 & Bolívia, Colômbia, Equador, Peru, Venezuela. \\
\hline $\begin{array}{l}\text { North American Plant Protection } \\
\text { Organization (NAPPO) }\end{array}$ & 1976 & Canadá, México, Estados Unidos. \\
\hline $\begin{array}{l}\text { Comité Regional de Sanidad Vegetal } \\
\text { para el Cono Sur (COSAVE) }\end{array}$ & 1980 & Argentina, Brasil, Chile, Paraguai, Uruguai, Peru (Bolívia, em processo de adesão). \\
\hline $\begin{array}{l}\text { Pacific Plant Protection } \\
\text { Organization (PPPO) }\end{array}$ & 1995 & $\begin{array}{l}\text { Austrália, Cook (Ilhas), Fiji, França (Polinésia Francesa, Nova Caledônia), Ilhas Wallis e } \\
\text { Futuna, Kiribati, Marshall (Ilhas), Micronésia, Nauru, Nova Zelândia, Niue (Ilha), Palau, } \\
\text { Papua-Nova Guiné, Samoa, Salomão (Ilhas), Tokelau, Tonga, Tuvalu, Estados Unidos } \\
\text { (Samoa Americana e Guam), Reino Unido (Pitcairn). }\end{array}$ \\
\hline
\end{tabular}

${ }^{(1)}$ Foi abolida em 2014, pela resolução 1/150 do conselho da FAO. 
mas exigem uma nova política fitossanitária, baseada em uma análise precisa dos riscos de entrada de pragas, e não na proibição geral da entrada de alguns produtos vegetais.

\section{Ferramentas analíticas: aderência às regras internacionais de análise fitossanitária}

As análises fitossanitárias de materiais vegetais devem ser realizadas por métodos oficiais adotados internacionalmente, que permitam confiabilidade e rastreabilidade dos resultados. Considerando-se que não há métodos perfeitos, resultados falso-positivos ou falso-negativos podem ser obtidos. Consequentemente, é necessário estimar a capacidade de cada técnica ou método, com o objetivo de minimizar a incerteza e melhorar a interpretação dos resultados (López et al., 2008). Protocolos são desenvolvidos e validados por organizações internacionais como a International Seed Testing Association (Ista). Algumas organizações regionais publicam, regularmente, protocolos diagnósticos detalhados e que incorporam as técnicas mais recentes disponíveis (Cosave, 2000; European and Mediterranean Plant Protection Organization, 2015). No Brasil, análises oficiais de diagnóstico fitossanitário são realizadas em laboratórios credenciados pelo Mapa, e a pesquisa científica contempla a elaboração de metodologias para a diagnose de pragas agrícolas. Em todos os casos, o funcionamento dos laboratórios credenciados, a fiscalização das instalações quarentenárias, assim como o fiel e seguro cumprimento das legislações vigentes são assegurados pelo Mapa, por meio dos Fiscais Federais Agropecuários.

\section{Ferramentas analíticas: acurácia do diagnóstico}

Detecções precoces não somente reduzem significativamente o risco de introdução e disseminação, como possibilitam a implementação de estratégias de erradicação e contingência (Grimshaw et al., 2006). As atividades quarentenárias requerem instalações apropriadas, equipamentos sofisticados e metodologia diagnóstica de última geração. Os métodos de diagnose devem ser muito precisos e limitar a ocorrência de falso-positivos e negativos. Um resultado falso-positivo pode gerar conflitos internacionais, enquanto um falso-negativo pode permitir a introdução de praga quarentenária, por isso, é indispensável a utilização de controles confiáveis. Ferramentas moleculares, baseadas em PCR quantitativo em tempo real (qPCR), têm sido aplicadas intensivamente em instituições internacionais, para a diagnose, considerandose a grande vantagem de redução do tempo de quarentena dos materiais (Sawazaki et al., 2013). Essa técnica, já considerada altamente sensível, teve sua sensibilidade melhorada em 100 vezes por agregação de procedimentos, para o diagnóstico de Synchytrium endobioticum em batata (Gent-Pelzer et al., 2010). $\mathrm{O}$ conhecimento acurado sobre os diferentes grupos de pragas permite o desenvolvimento de metodologias adequadas a cada caso, cujos requerimentos de segurança na manipulação, medidas de contenção e, até mesmo, de descarte são abordados com frequência (Phillipson, 2012). Outro fator determinante no estabelecimento de métodos diagnósticos é a formação contínua e específica de pessoal, assim como a montagem de estrutura física adequada e devidamente equipada.

\section{Consolidação das metodologias de análise de risco de pragas}

A estrutura e o delineamento de uma ARP são estabelecidos pela CIPV.A possibilidade de julgamentos subjetivos e sujeitos a questionamentos por parte de exportadores tem levado à busca de ferramentas analíticas padronizadas. Os métodos podem ser qualitativos, quantitativos ou semiquantitativos (Devorshak, 2012). Os métodos qualitativos são de fácil entendimento e podem ser utilizados com um menor volume de informações. A análise qualitativa é adequada ao uso de um sistema de graduação que pode ser verbal ou numérico, em que o risco é computado por meio de uma matriz. Diferentemente, os métodos quantitativos são baseados em modelos probabilísticos, e as probabilidades podem ser tratadas na forma de cadeia ou árvore linear de eventos (Griffin, 2012). Esses métodos são muito úteis para as avaliações de potencial de introdução (entrada e estabelecimento) e o potencial de dispersão de uma praga (Rafoss, 2003), mas, embora precisas, as ARPs puramente quantitativas são difíceis de serem realizadas, em razão da grande necessidade de dados, muitas vezes indisponíveis na literatura.

Atualmente, alguns programas podem ser utilizados para a elaboração de mapas de distribuição atual da praga e mapas do potencial de distribuição, com o uso de informações georreferenciadas como os dos programas OpenModeller (Muñoz et al., 2011), Climex v. 4 (Hearne Scientific Software Pty. Ltd., Melbourne, 
Austrália) e Programa R (The R Foundation, 2014). Modelos preditivos, baseados na utilização de informações climáticas, de presença da espécie ou dados sobre a biologia também estão disponíveis, como GARP (Genetic Algorithm for Rule Set Production), MaxEnt (Maximum Entropy), Climex e SOM (Self Organized Maps) (Elith \& Leathwick, 2009; Giannini et al., 2012). A qualidade dos dados iniciais, o método de análise e os parâmetros utilizados influenciam diretamente o resultado (Sutherst, 2014), assim como a participação de especialistas na validação do resultado.

Outro ponto importante na construção de uma ARP é o compartilhamento de informações. $\mathrm{O}$ acesso a banco de dados compartilhados por diferentes instituições é essencial para a elaboração de ARPs ou planos de contingência e de erradicação. A construção de informações, que inclua dados de interceptações de pragas ou do monitoramento de áreas sob risco de introdução, pode agilizar o processo de resposta dos órgãos responsáveis pela defesa fitossanitária (Hulme \& Roy, 2010).

Aanálise do potencial das consequências econômicas e de impactos ambientais também apresenta versões qualitativas e quantitativas. Em ambos os casos, elas devem ser claras, sustentadas pela literatura e pela descrição do cenário econômico (qualitativas); por orçamento parcial ou pelas sofisticadas técnicas de equilíbrio parcial e equilíbrio geral econômico (Soliman et al., 2010). É importante ressaltar que a abordagem é multidisciplinar, pois o potencial de consequências econômicas está diretamente relacionado ao potencial de dispersão das pragas a partir do seu estabelecimento. Até o momento, o Brasil não dispõe de um guia específico para a realização de ARPs, mas segue o delineamento descrito na NIMF 11. Para o nível regional, finalizou-se uma proposta que foi discutida no âmbito do Cosave desde 2009 e poderá ser adotada pelos países membros (Cosave, 2015).

\section{Perspectivas de inovação em quarentena vegetal}

A competitividade ante o agronegócio mundial e a dependência do país por recursos genéticos alimentícios exóticos têm feito com que o Brasil recorra continuamente à importação de germoplasma exótico, para fins de pesquisa em programas de melhoramento. Por outro lado, grandes volumes de produtos agrícolas no comércio internacional e a movimentação de pessoas no mundo também são fatores de risco de introdução de pragas (Eschen et al., 2015). Assim, é necessário que as regulamentações quarentenárias produzam um equilíbrio entre o nível de proteção fitossanitária, proporcionado pelas estações quarentenárias na importação de material para pesquisa, e o nível de proteção por ARP, na importação de material vegetal comercial. Material vegetal importado com um mesmo nível de risco (mesma origem, mesma parte vegetal e mesma finalidade) não pode estar sob regulamentações diferentes. Para atender a essa exigência, uma nova instrução normativa está sendo elaborada pelo Mapa.

Para importações de vegetais com finalidade de pesquisa, uma estrutura em rede composta por estações quarentenárias seria a conformação mais adequada, para atender as necessidades de proteção fitossanitária de um país com a extensão territorial do Brasil. Essas estações quarentenárias seriam especializadas em análise de determinados produtos, tais como as que existem em outros países. Esta especialização já está prevista pela instrução normativa (IN) que está em consulta pública e que tem base na NIMF 34 (International Plant Protection Convention, 2010) promovendo uma alteração substancial dos dispositivos da IN 16/1999.

As quarentenas não devem ser tecnicamente estáticas (Import risk analysis handbook, 2011). Métodos e equipamentos devem possibilitar o diagnóstico preciso da condição sanitária dos materiais em análise, e os equipamentos devem estar em consonância com os métodos mais acurados e modernos. A automação é fortemente desejável como meio de tornar o processo uniforme e conferir-lhe a rapidez possível, sem perda de segurança fitossanitária.

Todas as operações de quarentena devem ser conduzidas em instalações apropriadas ao confinamento e à segurança, a fim de evitar escape de organismos nocivos no meio ambiente (Legrand, 2012). Assim, a estrutura e operação de uma estação quarentenária são regulamentadas para fins de garantia de uma gestão do risco fitossanitário. No caso do Brasil, a regulamentação e a fiscalização das estações quarentenárias é realizada pelo Mapa. Em diferentes localidades, a disposição e dimensão das instalações adequam-se às possibilidades e condições locais, mas as premissas essenciais devem ser mantidas. Uma dessas premissas é a organização das estruturas para atender à sequência dos processos. 
O desenho mais desejável para um espaço destinado a quarentenas contempla locais distintos para materiais em análise e materiais prontos para liberação, de modo a minimizar a possibilidade de contaminação cruzada acidental (Kahn \& Mathur, 1999).

Um sistema de qualidade para as análises laboratoriais é constituído por um conjunto de ações pré-estabelecidas e sistemáticas, que visam garantir que as análises satisfaçam às exigências previstas. Os conceitos de qualidade adotados pelos laboratórios que emitem laudos são certificações que permitem a rastreabilidade. $\mathrm{O}$ conjunto de procedimentos deve oferecer aos usuários resultados cujas fontes de erro foram identificadas e cujas medidas de correção foram tomadas. As Boas Práticas de Laboratório (BPL) e a norma NBR ISO/IEC 17.025 (Associação Brasileira de Normas Técnicas, 2005) dão a garantia de que os resultados fornecidos pelo laboratório são obtidos e controlados de maneira coerente. Distinguemse, nessas normas, aspectos relativos a: pessoal (competência para as tarefas que efetua e supervisão adequada); instalações e materiais (arquitetura dos laboratórios, aparelhagem acompanhada de calibração e manutenção, reagentes identificados e armazenados adequadamente); técnicas (identificação precisa das amostras, descrição detalhada do modo de execução, anotação precisa, legível e indelével dos resultados, que são os registros da qualidade) (Lepoivre, 2003); e relativos também à gerência, no caso da ISO 17.025. Normas internacionais tendem a codificar todas as ações relativas à implantação de sistemas de qualidade em laboratórios de análise.

$\mathrm{O}$ processo de ARP é o fundamento das regulamentações fitossanitárias, e a sistematização das informações sobre as pragas agrícolas contribui para sua eficiência. Este cenário é favorável à integração de bases de dados criadas por entidades públicas, bem como um sistema de gerenciamento. Um exemplo de avanço para a melhoria das técnicas de ARP no mundo foi proporcionado pelo projeto Pratique (Enhacements of Pest Risk Analysis Techniques) da União Europeia (Baker et al., 2009). Este projeto desenvolveu uma plataforma computacional denominada Capra (Computer-Assisted Pest Risk Analysis) que incorporou várias melhorias e padronizações, em que um dos avanços foi a incorporação dos níveis de incerteza. A grande vantagem para o Brasil na adoção de um sistema semelhante seria uma padronização do procedimento e ganho de tempo. É importante ressaltar que as ARPs realizadas no âmbito da União Europeia não utilizam mais a organização de informação de pragas em fichas, como o sistema brasileiro, mas um conjunto de questões que são direcionadas aos pontos de avaliação de risco. A parametrização dos potenciais de risco também é computadorizada. Nesse caso, há um grande ganho de eficiência no processo de revisão, uma situação que é prevista pela CIPV, mas ainda não utilizada no Brasil.

Outro tópico que se beneficia com incorporações de avanços de outras áreas da ciência da computação é o da previsão de espécies invasoras. Redes neurais são particularmente úteis com mapas auto-organizáveis (self-organizing maps), promissores na identificação de ameaças de invasões de pragas (Paini et al., 2011). Novos métodos são desenvolvidos para facilitar a elaboração de planos de levantamentos para pragas emergentes (Parnell et al., 2014). Ferramentas dessa natureza trazem em si um forte componente de modernização das quarentenas, no direcionamento de esforços e tomadas de decisão.

Obras de referência em quarentena vegetal são publicadas com regularidade, com atualização sobre os diversos temas pertinentes às atividades quarentenárias, inclusive os regimes fitossanitários internacionais, esquemas de diagnose e a certificação (Berg, 1989; Ebbels, 2003; Sugayama et al., 2015).

A incorporação de inovações na atividade quarentenária ocorre no contexto normativo, local ou internacional. De acordo com Rossi (2014), "a inovação é estratégica e imperativa, sobretudo para o crescimento e sustentação das ações no longo prazo". Esse mesmo autor considera necessário que as organizações promovam ações sistêmicas e que sejam capazes de estruturar seus processos, motivar equipes e disseminar, internamente, os conceitos de inovação. $\mathrm{O}$ desafio é criar uma capacidade inovativa real que confira eficiência e eficácia à atividade quarentenária, consoantes com a globalização, a velocidade de deslocamentos, a soberania alimentar e a sustentabilidade indispensável ao momento presente.

\section{Considerações finais}

As quarentenas vegetais inscrevem-se no contexto da segurança nacional e desempenham um papel preponderante na proteção da biodiversidade, na 
sustentabilidade alimentar e ambiental e na provisão de energia limpa, ao executar as estratégias para a manutenção de organismos nocivos longe de cultivos agrícolas e matas nativas. $O$ serviço a ser prestado para a sociedade brasileira poderá ser mais eficaz, se estações quarentenárias forem estabelecidas em diversos pontos do país, funcionando de forma interligada, o que otimizará a vigilância necessária ao intercâmbio seguro de plantas e seus produtos, tanto na importação quanto na exportação. A adequação de instalações, de procedimentos e a automação operacional resultam na maximização da acurácia do diagnóstico fitossanitário e minimização dos riscos fitossanitários. Entretanto, permanece o desafio da emissão de laudos acreditados em sistema de qualidade, o que ainda é dispendioso e requer a quebra de resistência por parte do corpo técnico às mudanças em rotinas laboratoriais. Evidentemente, a preparação de estações quarentenárias completas é uma etapa do sistema de defesa sanitária vegetal, o qual é composto de diversos processos em um contexto muito amplo. Do ponto de vista da complexa legislação que suporta os sistemas de quarentena, o desafio é a revisão constante, visando sua adequação às novas tecnologias e à disponibilidade atual de meios de comunicação e deslocamentos. Avanços científicos e informatização na análise de risco de pragas poderá tornar essa ferramenta acessível, conferindo-lhe rapidez e, consequentemente, eficácia. A atualização permanente dos procedimentos e internalização de capacidade inovativa são requisitos indispensáveis aos avanços necessários a uma modernização premente dos sistemas de defesa fitossanitária no Brasil.

\section{Referências}

ALVES, H.T. Campanhas fitossanitárias nacionais. In: ENCONTRO NACIONAL DE FITOSSANITARISTAS, 1., 1980, Campinas. Anais. Campinas: [s.n.], 1980. p.15-27.

ANCONA, V.; APPEL, D.N.; FIGUEIREDO, P. de. Xylella fastidiosa: a model for analyzing agricultural biosecurity. Biosecurity and Bioterrorism: Biodefense Strategy, v.8, p.171-182, 2010.

ASSOCIAÇÃO BRASILEIRA DE NORMAS TÉCNICAS. NBR ISO/IEC 17025:2005: requisitos gerais para competência de laboratórios de ensaio e calibração. Rio de Janeiro: ABNT, 2005.

BAKER, R.H.A.; BATTISTI, A.; BREMMER, J.; KENIS, M.; MUMFORD, J.; PETTER, F.; SCHRADER, G.; BACHER, S.; DE BARRO, P.; HULME, P.E.; KARADJOVA, O.; LANSINK, A.O.; PRUVOST, O.; PYŠEK, P.; ROQUES, A.; BARANCHIKOV, Y.; SUN, J.-H. PRATIQUE: a research project to enhance pest risk analysis techniques in the European Union. EPPO Bulletin, v.39, p.87-93, 2009. DOI: 10.1111/j.1365-2338.2009.02246.x.

BEBBER, D.P.; HOLMES, T.; GURR, S.J. The global spread of crop pests and pathogens. Global Ecology and Biogeography, v.23, p.1398-1407, 2014. DOI: 10.1111/geb.12214.

BERG, G.H. La cuarentena vegetal: teoría y práctica. San Salvador: Organismo Internacional Regional de Sanidad Agropecuaria, 1989. 440p.

BRASIL. Ministério da Agricultura, Pecuária e Abastecimento. Instrução normativa $\mathrm{n}^{\circ} 1$, de 15 de dezembro de 1998. Normas para importação de material destinado a pesquisa científica. Diário Oficial [da] República Federativa do Brasil, 16 dez. 1998.

BRASIL. Ministério da Agricultura, Pecuária e Abastecimento. Instrução normativa $\mathrm{n}^{\circ} 6$, de 16 de maio de 2005 . Considera a necessidade de disciplinar as exigências de análises de risco de pragas. Diário Oficial [da] República Federativa do Brasil, 17 maio 2005.

COSAVE. Estándar regional en protección fitosanitaria. Sección VII - Procedimientos y métodos analíticos. 7.2. Armonización de procedimientos y métodos analiticos para plagas. Versión 2.3.5. 2000. Disponível em: <http://www.cosave.org/sites/default/ files/erpfs/st70200v020305_esp.html>. Acesso em: 13 fev. 2015.

COSAVE. Guía para el desarollo de análisis de riesgo de plagas (ARP). Disponível em : < http://www.cosave.org/sites/default/files/ resoluciones/anexos/Guia\%20de\%20ARP.doc $>$. Acesso em: 12 fev. 2015.

DEVORSHAK, C. (Ed.). Plant pest risk analysis: concepts and application. Wallingford: CABI, 2012. 296p. DOI: 10.1079/9781780640365.0000.

EBBELS, D.L. (Ed.). Principles of plant health and quarantine. Wallingford: CABI, 2003. 302p. DOI: 10.1079/9780851996806.0000.

ELITH, J.; LEATHWICK, J.R. Species distribution models: ecological explanation and prediction across space and time. Annual Review of Ecology, Evolution and Systematics, v.40, p.677-697, 2009. DOI: 10.1146/annurev.ecolsys.110308.120159.

ESCHEN, R.; BRITTON, K.; BROCKERHOFF, E.; BURGESS, T.; DALLEY, V.; EPANCHIN-NIELL, R.S.; GUPTA, K.; HARDY, G.; HUANG, Y.; KENIS, M.; KIMANI, E.; LI, H.-M.; OLSEN, S.; ORMROD, R.; OTIENO, W.; SADOF, C.; TADEU, E.; THEYSE, M. International variation in phytosanitary legislation and regulations governing importation of plants for planting. Environmental Science and Policy, v.51, p.228-237, 2015. DOI: 10.1016/j.envsci.2015.04.021.

EUROPEAN AND MEDITERRANEAN PLANT PROTECTION ORGANIZATION. EPPO standards - diagnostics. EPPO Bulletin, v.45, p.392-396, 2015. DOI: 10.1111/epp.12257.

FLETCHER, J.; STACK, J. Agricultural biosecurity: threats and impacts for plant pathogens. In: GLOBAL infectious disease surveillance and detection: assessing the challenges-finding solutions. Washington: The National Academies, 2007. p.86-94.

GENT-PELZER, M.P.E. van; KRIJGER, M.; BONANTS, P.J.M. Improved real-time PCR assay for detection of the quarantine potato pathogen, Synchytrium endobioticum, in zonal centrifuge extracts 
from soil and in plants. European Journal of Plant Pathology, v.126, p.129-133, 2010. DOI: 10.1007/s10658-009-9522-3.

GIANNINI, T.C.; SIQUEIRA, M.F.; ACOSTA, A.L.; BARRETO, F.C.C.; SARAIVA,A.M.;ALVES-DOS-SANTOS, I. Desafios atuais da modelagem preditiva de distribuição de espécies. Rodriguésia, v.63, p.1-17, 2012. DOI: 10.1590/S2175-78602012000300017.

GRIFFIN, R. Basic concepts in risk analysis. In: DEVORSHAK, C. (Ed.). Plant pest risk analysis: concepts and application. Wallingford: CABI, 2012. p.7-18. DOI: 10.1079/9781780640365.0007.

GRIMSHAW, J.F.; WATERHOUSE, B.M.; WEINERT, M.P. The value of early detection and internal quarantine boundaries in the management of incursions: some examples in plant protection from northern Australia and Papua New Guinea. ACIAR Technical Reports Series, v.62, p.154-160, 2006.

HULME, P.E.; ROY, D.B. DAISIE and arthropod invasions in Europe. BioRisk, v.4, p.1-3, 2010. DOI: 10.3897/biorisk.4.41.

IMPORT risk analysis handbook. Canberra: Australian Government Department of Agriculture, Fisheries and Forestry, 2011. 49p.

INTERNATIONAL PLANT PROTECTION CONVENTION. International Standards for Phytosanitary Measures (ISPMs). Rome: Secretariat of the International Plant Protection Convention, Food and Agriculture Organization of the United Nations, 2006a. 291p.Disponível em: <ftp://ftp.fao.org/docrep/fao/009/a0450e/ a0450e.pdf $>$. Acesso em: 23 Jan. 2014.

INTERNATIONAL PLANT PROTECTION CONVENTION. ISPM 5: glossary of phytosanitary terms. Rome: Secretariat of the International Plant Protection Convention, Food and Agriculture Organization of the United Nations, 2006b. 23p.

INTERNATIONAL PLANT PROTECTION CONVENTION. ISPM 11: pest risk analysis for quarantine pests. Rome: Secretariat of the International Plant Protection Convention, Food and Agriculture Organization of the United Nations, 2013. 36p.

INTERNATIONAL PLANT PROTECTION CONVENTION. ISPM 34: design and operation of post-entry quarantine stations for plants. Rome: Secretariat of the International Plant Protection Convention, Food and Agriculture Organization of the United Nations, 2010. 14p.

KAHN, R.P.; MATHUR, S.B. (Ed.). Containment facilities and safeguards for exotic plant pathogens and pests. St. Paul: American Phytopathological Society, 1999. 213p.

LEBAS, B.S.M.; OCHOA-CORONA, F.M.; ELLIOTT, D.R.; TANG, J.; BLOUIN, A.G.; TIMUDO, O.E.; GANEV, S.; ALEXANDER, B.J.R. Investigation of an outbreak of Soil-borne wheat mosaic virus in New Zealand. Australasian Plant Pathology, v.38, p.85-89, 2009. DOI: 10.1071/AP08082.

LEGRAND, P. Importations de vigne dans l'Union européenne et securité phytosanitaire: le role indispensable de la quarantaine. Bulletin de l'OIV, v.85, p.481-492, 2012.

LEPOIVRE, P. Les aspects légaux de la lutte contre les maladies des plantes. In: LEPOIVRE, P. (Ed.). Phytopathologie: bases moléculaires et biologiques des pathosytèmes et fondements des stratégies de lutte. Bruxelas: De Boeck \& Larcier, 2003. p.231-241.
LÓPEZ, M.M.; LLOP, P.; OLMOS, A.; MARCO-NOALES, E.; CAMBRA, M.; BERTOLINI, E. Are molecular tools solving the challenges posed by detection of plant pathogenic bacteria and viruses? Current Issues in Molecular Biology, v.11, p.13-46, 2008.

MARINHO, V.L. de A. Abertura das fronteiras entre os países do Cone Sul e a nova política brasileira de gestão de riscos fitossanitários. Brasília: Embrapa Recursos Genéticos e Biotecnologia, 2001. 17p. (Embrapa Recursos Genéticos e Biotecnologia. Documentos, 50).

MARQUES, A.S.A.; FERNANDES, F.R. Risco de introdução de pragas exóticas nas principais culturas agrícolas. In: VEIGA, R.F. de A.; QUEIRÓZ, M.A. de. (Ed.). Recursos fitogenéticos: a base da agricultura sustentável no Brasil. Viçosa: Ed. UFV, 2015. p.176-182.

MIRANDA, S.H.G. de; CUNHA FILHO, J.H.; BURNQUIST, H.L.; BARROS, G.S.A. de C. Normas sanitárias e fitossanitárias: proteção ou protecionismo. Informações Econômicas, v.34, p.25-35, 2004.

MUÑOZ, M.E.S.; GIOVANNI, R.; SIQUEIRA, M.F.; SUTTON, T.; BREWER, P.; PEREIRA, R.S.; CANHOS, D.A.L.; CANHOS, V.P. OpenModeller: a generic approach to species' potential distribution modelling. GeoInformatica, v.15, p.111-135, 2001. DOI: 10.1007/s10707-009-0090-7.

NÓBREGA, H.B. Manual de inspeção fitossanitária do trânsito internacional e interestadual. Rio de Janeiro: Delegacia Federal de Agricultura, Ministério da Agricultura, 1987. 332p.

OCHOA-CORONA, F.M. Biosecurity, microbial forensics and plant pathology: education challenges, overlapping disciplines and research needs. Australasian Plant Pathology, v.40, p.335-338, 2011. DOI: 10.1007/s13313-011-0052-z.

PAINI, D.R.; BIANCHI, F.J.J.A.; NORTHFIELD, T.D.; DE BARRO, P.J. Predicting invasive fungal pathogens using invasive pest assemblages: testing model predictions in a virtual world. PLoS ONE, v.6 e25695, 2011. DOI: 10.1371/journal.pone.0025695.

PARNELL, S.; GOTTWALD, T.R.; RILEY, T.; BOSCH, F. van den. A generic risk-based surveying method for invading plant pathogens. Ecological Applications, v.24, p.779-790, 2014. DOI: 10.1890/13-0704.1.

PHILLIPSON, B. Quarantine procedures for working with fungal plant pathogens. In: LANE, C.; BEALES, P.; HUGHES, K.J.D. (Ed.). Fungal plant pathogens. Wallingford: CABI, 2012. p.251-270. DOI: $10.1079 / 9781845936686.0251$.

RAFOSS, T. Spatial stochastic simulation offers potential as a quantitative method for pest risk analysis. Risk Analysis, v.23, p.651-661, 2003. DOI: 10.1111/1539-6924.00344.

ROSSI, A.L. A inovação é realmente uma opção estratégica para as organizações? In: FOLZ, C.J.; CARVALHO, F.H.T. de. (Ed.). Ecossistema inovação. Brasília: Embrapa, 2014. p.31-47.

SAWAZAKI, H.E.; SÁ, L.A.N. de; GONÇALVES, C.R.N.C.B.; VEIGA, R.F.A.; COLOMBO, C.A. Molecular diagnosis optimization of virus, bacteria and fungi in sugarcane. International Research Journal of Plant Science, v.4, p.76-83, 2013. 
SCHUMANN, G.L.; D’ARCY, C.J. Hungry planet: stories of plant diseases. St. Paul: American Phytopathological Society, 2012. 294p.

SHARMA, S.; THAKUR, M. Role of plant quarantine in the management of pest organisms - a review. Agricultural Reviews, v.28, p.235-244, 2007.

SILVA, O.L.R. A globalização e a nova política de defesa sanitária vegetal. Fitopatologia Brasileira, v.25, p.234-235, 2000.

SOLIMAN, T.; MOURITS, M.C.M.; OUDE LANSINK, A.G.J.M.; WERF, W. van der. Economic impact assessment in pest risk analysis. Crop Protection, v.29, p.517-524, 2010. DOI: 10.1016/j. cropro.2009.12.014.

SUGAYAMA, R.L.; SILVA, M.L. da; SILVA, S.X. de B.; RIBEIRO, L.C.; RANGEL, L.E.P. Defesa vegetal: fundamentos, ferramentas, política e perspectivas. Belo Horizonte: Sociedade Brasileira de Defesa Agropecuária, 2015. 544p.
SUTHERST, R.W. Pest species distribution modelling: origins and lessons from history. Biological Invasions, v.16, p.239-256, 2014. DOI: $10.1007 / \mathrm{s} 10530-013-0523-y$.

THE R FOUNDATION. The R Project for Statistical Computing. Disponível em: <https://www.r-project.org/>. Acesso em: 23 Jan. 2014.

VEIGA, R.F. de A.; PREZOTTO, T.; BASSETTO, J.L. Introdução de germoplasma de espécies ornamentais nativas e exóticas. 2007. Disponível em: <http://www.infobibos.com/Artigos/2007_3/ Germo/Index.htm>. Acesso em: 21 maio 2015.

WATERWORTH, H.E.; WHITE, G.A. Plant introductions and quarantine: the need for both. Plant Disease, v.66, p.87-90, 1982. DOI: 10.1094/PD-66-87.

WORLD TRADE ORGANIZATION. The WTO agreement on the application of sanitary and phytosanitary measures (SPS agreement). 1995. Disponível em: <http://www.wto.org/english/ tratop_e/sps_e/spsagr_e.htm>. Acesso em: 10 fev. 2015.

Recebido em 1 de julho de 2015 e aprovado em 7 de março de 2016 